\title{
THE SIMULTANEOUS ORAL ADMINISTRATION OF SALMONELLA DUBLIN, S. TYPHIMURIUM AND S. CHOLERAESUIS TO CALVES AND OTHER ANIMALS
}

\author{
H. Williams Smith and Sheila Halls \\ Animal Health Trust, Stock, Essex
}

Although under natural conditions some Salmonella serotypes, e.g., S. typhimurium, infect many animal species, the host range of others is limited; in some cases, e.g., S. typhi, the organism is naturally pathogenic to one species only. The reason for this is not known. In the hope of throwing light upon the subject we gave mixtures of cultures of $S$. dublin, $S$. typhimurium and $S$. choleraesuis to calves by mouth. The animals were killed at different times afterwards and the distribution of the 3 serotypes in the tissues studied. S. dublin and S. typhimurium, between them, are responsible for the majority of natural salmonella infections that occur in calves. By contrast, $S$. choleraesuis is rarely found in these animals. For example, Buxton (1957), in a survey of the literature, reported only 2 records of the isolation of this serotype from cattle; its principal host is the pig. The calf studies were extended on a limited scale to include rabbits, mice and fowls.

\section{MATERIALS AND METHODS}

Calves. The calves were males of the Jersey breed aged 2-10 days when put under experiment. All had received colostrum, and examination of their sera by the zinc sulphate turbidity test (Aschaffenburg, 1949) revealed that they had absorbed an adequate amount of immune globulins from it. They were given 1 litre of reconstituted dried milk twice daily by bucket.

Method of producing infection in calves. Separate nutrient agar cultures of an ampicillinresistant mutant of $S$. dublin, a nalidixic acid-resistant mutant of $S$. typhimurium and a streptomycin-resistant mutant of $S$. choleraesuis were incubated at $37^{\circ} \mathrm{C}$ for $18 \mathrm{hr}$; all 3 mutants were smooth as judged by the slide acriflavine test of Braun and Bonestell (1947). The bacteria were washed off with phosphate buffer $\left(\mathrm{Na}_{2} \mathrm{HPO}_{4}, 1.5 \mathrm{~g} ; \mathrm{KH}_{2} \mathrm{PO}_{4}, 0.85 \mathrm{~g}\right.$;

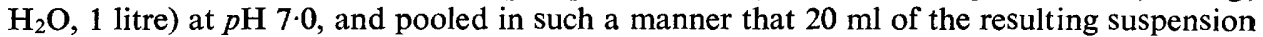
contained approximately $10^{10}$ viable organisms of each of the 3 serotypes. This amount or dilutions of it was added to a $\mathbf{0 . 5}$-litre volume of reconstituted milk and given to a calf to drink.

Examination procedure for calves. At the chosen time, calves were killed by the intravenous injection of sufficient pentobarbitone sodium followed by the severing of the carotid arteries. With sterile precautions the abdomen was opened quickly and ligatures applied to the duodenum close to the abomasum, to the ileum close to the caecum, to the posterior rectum and at numerous points along the small intestine. The whole alimentary tract was then removed and unravelled; the small intestine was arranged into 7 equal parts and the ligatures not needed to separate these parts were removed. The contents of the rumen, the abomasum, the 1st, 3rd, 5th and 7th parts of the small intestine and the colon were then

Received 5 Apr. 1968; accepted 23 May 1968.

J. MED. MCROBIOL.-VOL. 1 (1968) 
collected. The mucosa of these 4 parts of the small intestine was washed in running tapwater and then scraped with a scalpel; the material so removed was diluted 10 -fold with phosphate buffer and shaken with glass beads in a shaking machine. Approximately 2-g amounts of different organs, including a mesenteric lymph-gland draining each of the four parts of the small intestine previously mentioned, were removed with sterile instruments, dipped into 90 per cent. ethanol, flamed, and ground with sterile sand in a sterile pestle and mortar for $3 \mathrm{~min}$. This grinding procedure was shown previously to be adequate for enumerating Escherichia coli organisms in the tissues of calves (Smith and Halls, 1968). Body fluids were removed with sterile pipettes.

We then estimated the numbers of viable organisms of each of the 3 different salmonella serotypes in the materials referred to above by the method of Miles and Misra (Miles, Misra and Irwin, 1938), employing 3 kinds of brilliant green agar (Oxoid CM263), which differed according to whether they contained ampicillin, nalidixic acid or streptomycin sulphate at a concentration of $25 \mu \mathrm{g}$ per $\mathrm{ml}$. With this technique, the numbers of organisms could usually be estimated when they were as low as 50 per g. In addition, a specimen of each material was incubated in brilliant green broth (Smith, 1952) for $18 \mathrm{hr}$ and then subcultured on the 3 kinds of drug-containing brilliant green agar. Brilliant green broth was used in preference to selenite or tetrathionate broth because the latter two media are unsuitable for culturing $S$. choleraesuis.

The techniques employed in the studies on rabbits, mice and fowls were essentially the same as those for the calves except that the range of materials submitted to bacteriological examination was less. The materials examined were the wall and contents of the 1st and 2nd half of the small intestine, the contents of the colon of the rabbits and mice, the contents of the caeca of the fowls, the pooled mesenteric lymph-glands of each mouse and rabbit, and the blood, spleen, liver, bile, kidney and the lung of all 3 species.

\section{RESULTS}

\section{Oral administration of mixtures of viable organisms of Salmonella dublin, S. typhimurium and S. choleraesuis to calves}

The results of the bacteriological examinations of 9 calves killed at different times after oral administration of suspensions containing $10^{10}$ viable organisms of each of the 3 serotypes, S. dublin, S. typhimurium and S. choleraesuis, are summarised in table I. These depict a rapid penetration of the alimentary tract by salmonella organisms and the development of bacteriaemia with localisation and multiplication of organisms in the internal organs, particularly those rich in reticulo-endothelial cells. Whereas calves killed in the early stages of infection had greater numbers of organisms in the intestinal contents than in the wall of the intestine and the associated mesenteric lymph-glands, those killed in the later stages had the highest concentrations of organisms in the intestinal walls and in the mesenteric lymph-glands. Table II shows the concentrations of the three serotypes in the liver and intestinal content of these calves; in the liver the concentration of $S$. typhimurium tends to be a little lower than that of the other two serotypes, but in neither liver nor intestinal content is any one serotype markedly dominant. The findings in the other internal organs of these calves were very similar.

None of the 5 calves killed within 2 days of administration of the salmonellae had shown any signs of ill health. The one killed at 2 days appeared mildly ill and all three killed later were severely ill. The principal lesion in these 4 calves was a complete necrosis of the mucosa of the lower one-third of the ileum; in 
TABLE I

The numbers of viable Salmonella organisms in calves at different times after oral challenge with $10^{10}$ viable organisms of each of the 3 serotypes: Salmonella dublin, S. typhimurium and $S$. choleraesuis

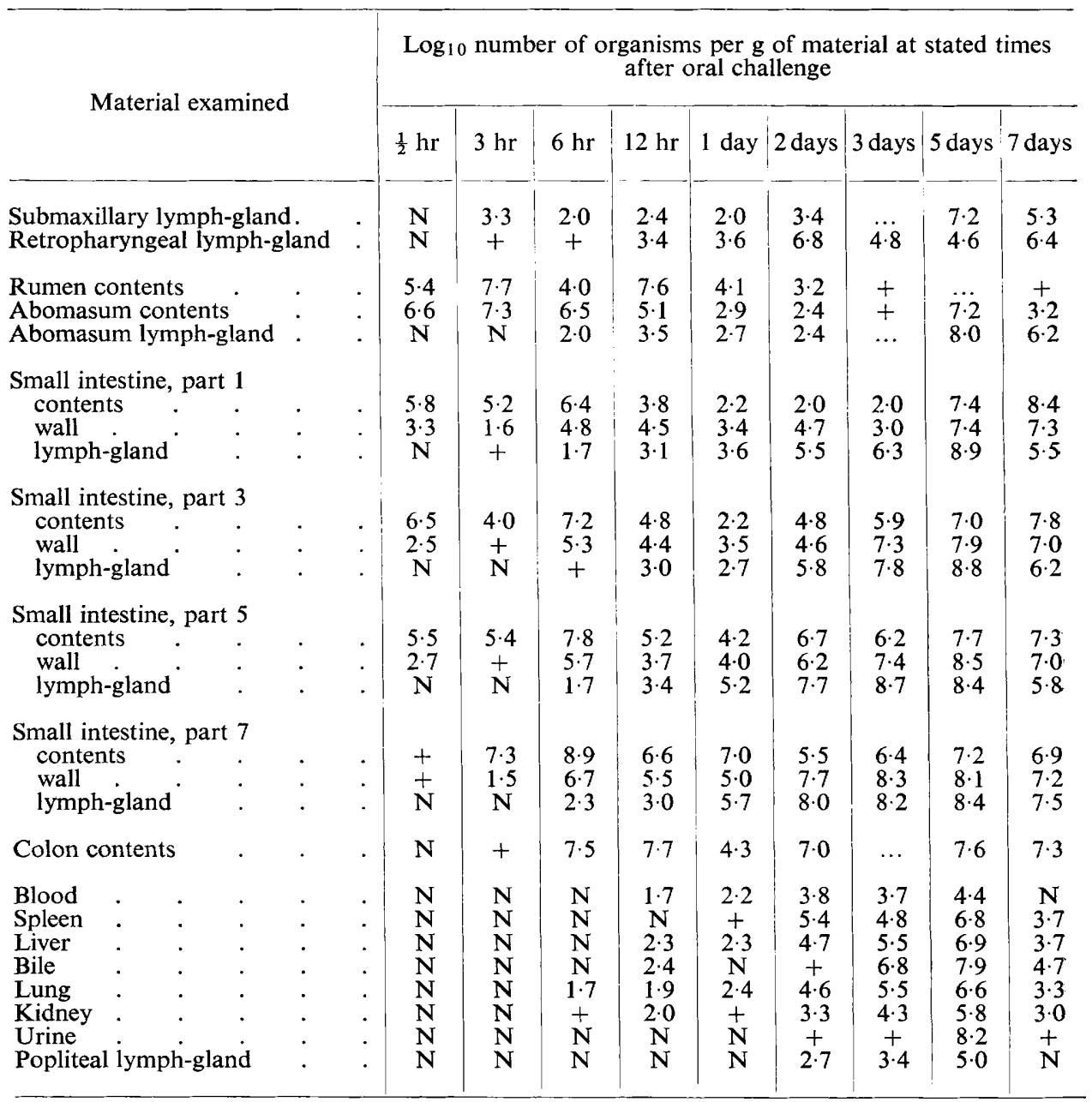

The small intestine was divided into 7 equal parts; part 1 was nearest to the abomasum and part 7 adjacent to the caecum.

$\mathrm{N}=$ No viable organisms found in $0.02 \mathrm{~g}$.

$+=$ Organisms found only after enrichment in brilliant green broth.

two of them the necrosis also involved the caecum. Some necrosis of the terminal ileum was observed in the calf killed 1 day after inoculation.

\section{Oral challenge of calves with reduced doses of $S$. dublin, S. typhimurium and $S$. choleraesuis}

Graded doses of the salmonella mixture were prepared containing $10^{7}, 10^{6}$, $10^{5}$ and $10^{4}$ viable organisms of each of the 3 serotypes and these were given 
to individual calves; the test with the mixture at the $10^{6}$ dose level was duplicated with 2 calves. The calf given the $10^{7}$ dose and one of the two given the $10^{6}$ dose were killed 5 and 7 days respectively after challenge, when they were very ill. The other calf given the $10^{6}$ dose and those given the $10^{5}$ and $10^{4}$ doses were killed 4, 10 and 5 days respectively after challenge; these 3 animals had never appeared unwell and no lesions were found in them. The relative distribution of organisms of the 3 serotypes in the 5 calves was similar to that

\section{TABLE II}

The numbers of $S$. dublin, S. typhimurium and $S$. choleraesuis in the liver and in the contents of the small intestine of calves at different times after oral challenge with 1010 viable organisms of each serotype

\begin{tabular}{|c|c|c|c|c|c|c|c|c|c|c|}
\hline \multirow{2}{*}{$\begin{array}{l}\text { Material } \\
\text { examined }\end{array}$} & \multirow{2}{*}{$\begin{array}{c}\text { Serotype } \\
\text { administered } \\
\text { and recovered }\end{array}$} & \multicolumn{9}{|c|}{$\begin{array}{c}\log _{10} \text { number of viable organisms per } \mathrm{g} \text { of material from calf } \\
\text { killed at stated time after challenge }\end{array}$} \\
\hline & & $\frac{1}{2} \mathrm{hr}$ & $4 \mathrm{hr}$ & $6 \mathrm{hr}$ & $12 \mathrm{hr}$ & 1 day & 2 days & 3 days & 5 days & 7 days \\
\hline Liver & $\begin{array}{l}\text { S. dublin } \\
\text { S. typhimurium } \\
\text { S. choleraesuis }\end{array}$ & $\begin{array}{l}N^{+} \\
N\end{array}$ & $\begin{array}{l}\mathbf{N} \\
\mathbf{N}\end{array}$ & $\begin{array}{l}\mathbf{N} \\
\mathbf{N}\end{array}$ & $\begin{array}{l}2 \cdot 0 \\
2 \cdot 0 \\
N\end{array}$ & $\begin{array}{l}\mathbf{N} \\
2 \cdot 0 \\
2 \cdot 0\end{array}$ & $\begin{array}{l}3 \cdot 4 \\
3 \cdot 4 \\
4 \cdot 7\end{array}$ & $\begin{array}{l}5 \cdot 0 \\
3 \cdot 6 \\
5 \cdot 3\end{array}$ & $\begin{array}{l}6 \cdot 7 \\
5 \cdot 4 \\
6 \cdot 5\end{array}$ & $\begin{array}{l}1 \cdot 7 \\
2 \cdot 2 \\
3 \cdot 7\end{array}$ \\
\hline $\begin{array}{l}\text { Contents of } \\
\text { small } \\
\text { intestine } \\
\text { (part } 7)^{*}\end{array}$ & $\begin{array}{l}\text { S. dublin } \\
\text { S. typhimurium } \\
\text { S. choleraesuis }\end{array}$ & $\begin{array}{l}++ \\
+ \\
+\end{array}$ & $\begin{array}{l}7 \cdot 3 \\
5 \cdot 5\end{array}$ & $\begin{array}{l}7 \cdot 4 \\
8 \cdot 2 \\
6 \cdot 8\end{array}$ & $\begin{array}{l}5 \cdot 7 \\
6 \cdot 5 \\
4 \cdot 0\end{array}$ & $\begin{array}{l}4 \cdot 8 \\
7 \cdot 0 \\
5 \cdot 3\end{array}$ & $\begin{array}{l}5 \cdot 4 \\
3 \cdot 7 \\
4 \cdot 4\end{array}$ & $\begin{array}{l}4 \cdot 0 \\
2 \cdot 4 \\
6 \cdot 4\end{array}$ & $\begin{array}{l}6 \cdot 5 \\
6 \cdot 8 \\
6 \cdot 8\end{array}$ & $\begin{array}{l}6 \cdot 0 \\
6 \cdot 8 \\
6 \cdot 0\end{array}$ \\
\hline
\end{tabular}

* Part 7 was the part of the small intestine next to the caecum.

$\dagger+=$ Organisms found only after enrichment in brilliant green broth.

$+\mathrm{N}=$ No viable organisms found in $0.02 \mathrm{~g}$.

found in the calves in the previous experiments, the actual numbers of organisms present being low in the 3 that had never appeared unwell. The calf given the $10^{4}$ dose was exceptional in that salmonellae were found only in the spleen, the intestinal contents and mesenteric lymph-glands. S. choleraesuis featured at least as prominently as the other 2 serotypes in all the cultures prepared from these 5 calves.

\section{Oral challenge of calves with $S$. choleraesuis only}

Two calves were given $10^{10}$ viable organisms of $S$. choleraesuis only. One died 3 days later and the other 4 days later. At necropsy, performed soon after death, the principal lesion observed was complete necrosis of the lower one-third of the ileum; large numbers of $S$. choleraesuis were present in the contents and the lymph-glands of the alimentary tract and in the internal organs.

\section{Oral challenge of animals other than calves}

Rabbits. Four adult rabbits were examined 7 days after oral challenge with a mixture containing $5 \times 10^{9}$ viable organisms of each of the 3 serotypes: S. dublin, 
$S$. typhimurium and $S$. choleraesuis; by this time the animals were unwell. $S$. typhimurium and $S$. choleraesuis were present in the contents of the small intestine and colon of all of the rabbits, the concentrations of $S$. typhimurium tending to be higher than those of $S$. choleraesuis. $S$. dublin was found in the alimentary tract of only one rabbit; it was in the colon contents in low concentration. Moderately high concentrations of $S$. choleraesuis were present in most of the internal organs of all 4 rabbits; the $\log _{10}$ numbers of these organisms in the spleen, for example, were $4 \cdot 4,4 \cdot 8,5 \cdot 3$ and 6.0 per g. By contrast, the only organs from which $S$. dublin and $S$. typhimurium were isolated were the mesenteric lymph-glands.

Mice. Nine adult white Swiss mice were challenged orally with $10^{8}$ viable organisms of each of the 3 serotypes: $S$. dublin, S. typhimurium and S. choleraesuis. The mice appeared unwell when killed 4-15 days later. S. dublin and $S$. typhimurium were isolated from the alimentary contents of all 9 mice. In six of them the concentrations of $S$. dublin were greater than those of $S$. typhimurium, being present in the colonic contents in $\log _{10}$ numbers of $1 \cdot 7-7 \cdot 7$ (median 5.2) per g. By contrast, S. choleraesuis was found in the alimentary tract of only one mouse but in high concentrations. It was also present in high concentration in the internal organs of this mouse. It was not isolated from any site in the remaining 8 mice. $S$. dublin was the predominant serotype isolated from the internal organs of all 9 mice. The $\log _{10}$ numbers of viable organisms of this serotype in the spleen were $2 \cdot 8-6.8$ (median $6 \cdot 2$ ) per $\mathrm{g}$; it was also found in the blood of 7 of them. S. typhimurium was present in the internal organs of 4 mice but in concentrations very much lower than those of S. dublin.

Fowls. Five 7-wk-old fowls were similarly challenged orally with mixtures of $3 \times 10^{9}$ viable organisms of each of the 3 serotypes. The fowls were killed 2-7 days later; none of them had appeared unwell. Only very low concentrations of salmonellae, principally $S$. typhimurium, were found in the contents of their alimentary tracts. No organisms were isolated from their internal organs.

Another 6 fowls were given $3 \times 10^{9}$ viable organisms of the $S$. dublin strain together with similar doses of a nalidixic acid-resistant mutant of $S$. gallinarum and a streptomycin-resistant mutant of $S$. pullorum. These fowls were killed 1-10 days later; those killed during the latter half of this period appeared unwell. Organisms of all 3 serotypes were found in small numbers in the contents of the alimentary tracts, particularly the caeca, of most of the fowls. $S$. gallinarum was present in moderately high concentrations in most of the internal organs of 4 fowls; it was found in the blood of 3 of them. S. dublin was isolated from the liver of one fowl and S. pullorum from the kidney of another; organisms of these 2 serotypes were not found in any of the organs of the other fowls.

\section{Discussion}

A limitation of the present work was that only one strain of each salmonella serotype was studied; if other strains had been employed, different results might have been obtained. The results obtained with the fowls, however, were 
compatible with the fact that $S$. gallinarum is the only serotype that causes clinical salmonella infection in adult fowls under natural conditions. The complete dominance of $S$. choleraesuis over $S$. dublin and $S$. typhimurium in the internal organs of the rabbits was also expected because rabbits are known to be highly susceptible to fatal infection with this serotype. Although strains of $S$. choleraesuis exist that produce severe disease in mice after oral administration (Smith, 1965), the strain used in the present studies proliferated in only 1 of 9 mice challenged; this is at least in agreement with the knowledge that strains of this serotype rarely, if ever, cause natural outbreaks of salmonella infection in mice. The situation in experiments with the calves was quite different, because $S$. choleraesuis undoubtedly played an important part in the pathological process that developed in all those given the larger dose of the 3 salmonella serotypes. Also, in the calves given the smaller dose, $S$. choleraesuis was as numerous as $S$. dublin and $S$. typhimurium in the organs and in the contents of the alimentary tract. Moreover, $S$. choleraesuis produced severe disease when administered alone to calves. No explanation, therefore, can be offered to account for the fact that this serotype rarely if ever gives rise to natural outbreaks of clinical disease in calves.

Oral challenge of calves with $10^{10}$ viable organisms of each of the 3 serotypes, S. dublin, S. typhimurium and S. choleraesuis, produced a disease that did not differ appreciably from that produced by the same dose of $S$. choleraesuis alone. Neither did it differ appreciably from that produced by $S$. dublin alone (Smith and Jones, 1967) or S. typhimurium alone (Rankin, Taylor and Newman, 1967). Since necrosis is commonly regarded as a sign of the chronicity of a disease process it is noteworthy that it was macroscopically evident in the mucous membrane of the ileum of a calf killed in the present investigation only $24 \mathrm{hr}$ after oral inoculation. The rapidity with which organisms reached the internal organs after oral administration and their frequent isolation from the glands of the mouth and pharynx, indicating the importance of this lymphatic avenue of invasion, were also features of experimental S. typhimurium infection noted in calves by De Jong and Ekdahl (1965).

\section{SUMMARY}

Simultaneous oral challenge of calves with $S$. dublin, S. typhimurium and $S$. choleraesuis produced a severe disease essentially similar to that produced by giving one of the serotypes alone. In general, organisms of the three serotypes were similarly distributed throughout the contents of the alimentary tract and the tissues. This applied even when the challenge dose of each of the three serotypes was reduced to $10^{4}$.

The distribution of organisms was different in rabbits, mice and fowls simultaneously challenged with these three serotypes.

We are grateful to Mr T. Humphrey, Miss Diane Poulton and Miss Carole Smith for their capable technical help. Our thanks are also due to Mr L. J. Abbott, Mrs Esther Johnson and Dr K. C. Sellers for advice and assistance in various ways. 


\section{REFERENCES}

AsCHAFFENBURG, R. . $\quad$ • $\quad$. $\quad$. 1949. Br. J. Nutr., 3, 200.

Braun, W., and Bonestell, Aileen E. • 1947. Amer. J. Vet. Res., 8, 386.

Buxton, A. . . . . . 1957. Salmonellosis in animals, Farnham

DE JoNG, H., AND Ekdahl, M. O. 1965. N.Z. Vet. J., 13, 59.

Miles, A. A., MisRA, S. S., AND Irwin, 1938. J. Hyg., Camb., 38, 732. J. $O$.

Rankin, J. D., TAYloR, R. J., AND 1967. Vet. Rec., 80, 720.

NeWman, G.

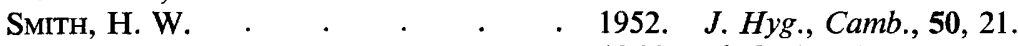

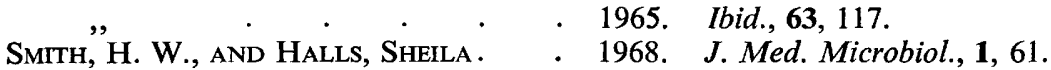

Smith, H. W., AND Jones, J. E. T. . . 1967. J. Path. Bact., 93, 141. 